\title{
Peculiarities of Interlocutors' Verbal Communicative Behavior in Apology Situation
}

\author{
Yuliya Tufanova \\ Institute of Linguistics and Cross-Cultural Communication, Irkutsk National Research Technical University, Irkutsk, Russia
}

\begin{abstract}
The article discusses the situation of apology, which plays an important role in maintaining the communicative balance in daily social interaction. The research aims at analyzing the peculiarities of interlocutors' verbal behavior in the situation in the context of the communicative-pragmatic approach. The structural parameters of the situation and the mutual influence of its components are described. The study investigates the functional features of linguistic politeness in the communicative situation. As indicated by the data, collected cooperative communicative behavior in apology situation is associated with the use of etiquette fixed formulas and free statements, acting as an apology in typical situations, which promotes effective interaction. Based on the analysis carried out, the traditional (etiquette) view of the situation is specified. In particular, the findings show that interlocutors' verbal communicative behavior in apology situation, reflecting their psycho-emotional state, the level of culture, personal characteristics, may be not only cooperative but also conflict-oriented. In cases when the intentions of interlocutors collide the situation reorganizes and acquires a conflict nature.
\end{abstract}

\section{Introduction}

There is at present a strong and increasing interest in interpersonal communication process. Communication is an integral part of human life and it forms the basis of any society existence. Anthropocentric orientation of modern linguistics is manifested in addressing the issues of daily social interaction. As a result, a growing number of current studies are focused on the problems of verbal/nonverbal human communication [1-9].

Apology as an important component of natural life interaction plays a significant role in everyday communicative situations. The study of the apology situation can provide us with better understanding and new insights into the process of human interaction. In this context, the relevance of the chosen topic is determined by: 1) the focus of modern linguistic science on the study of human communication and problems of communicative behavior; 2) the need to expand knowledge about the realization patterns of interpersonal communication; 3 ) the importance of apology in various spheres of human social interaction as a way of preserving harmonious relationships between communicants; 4) the inadequate elaboration of issues related to communicative interaction and verbal behavior of interlocutors in apology situation.

The study is based on the following hypothesis: the interlocutors' verbal communicative behavior in apology situation, determined by their psycho-emotional state, the level of culture, intentions, views, assessments, attitudes, goals, may be not only cooperative but also conflictoriented.
The objective of this paper is to identify the specifics of verbal communicative behavior of participants in apology situation. To achieve the goal, we need to solve the following tasks: 1) to clarify the apparatus of the initial concepts needed for the study; 2) to systematize the results of empirical studies relevant to the subject matter of the work; 3) to identify the main characteristics of participants' cooperative and conflictual communicative behavior in apology situation. A set of theoretical and empirical research methods was used to solve these problems: the technique of observation and interpretation, the component and functional-semantic analysis, the modeling technique.

The scientific novelty of the research is due to the verification on fairly extensive empirical data the hypothesis about the often emerging conflictual orientation of participants' communicative behavior in the apology situation; the clarification of the traditional (etiquette) concept of the situation.

In the study, the written text is considered as a representation of communicative and pragmatic potential of the verbal means of expressing the speech intentions of participants in the apology situation. The research is based on data drawn mainly from fiction texts of Russian and English-speaking writers of the XIX - early XXI century (12,771 pages). Data of the British National Corps (BNC), data of the electronic catalog "Digitale Bibliothek: English and American Literature", texts of Internet sites, dictionaries and encyclopedic publications were used. The research body was about 1500 examples of dialogical speech.

*Corresponding author: ttufanova@mail.ru 


\section{Cooperative communicative behavior}

In a broad sense, communicative behavior is a set of communication norms and traditions of a certain group of people, which describes the real communicative practice. By verbal communicative behavior we mean the set of norms and traditions of human interaction, related to the subject and features of communication organization in certain communicative environment [10]. In natural life communicative situations, we are considering such etiquette verbal actions as a greeting, a compliment, an expression of gratitude, congratulations and the apology. They allow the speaker to focus on the «implications» of his actions, to inform about the respect for the addressee or «to that institution, the representative or symbol of which he is» [11], to show friendliness «relying on the personal social experience and generally accepted norms of behavior in various situations» [12]. Such «respectful» actions correlate with the rules of human behavior accepted in each specific society.

Similarly, norms and rules of behavior correlate with the speaker's responsibilities and communicative expectations of the addressee. With their help, the speaker shows his attitude to the addressee and, consequently, in what way he intends to communicate with him. This behavior works for a positive image of the addressee. E. Hoffman notes that the balance between prohibitive strategies and «respectful» actions causes a «mobile equilibrium point» or «immanent contradiction» between the desire to do a good deed and intruding on «someone else's» territory [11]. At the same time, cooperative communicative behavior is characterized by a priority focus on the interlocutor, a positive tonality of communication, «a manifestation of friendly relations, which is expressed by various verbal and nonverbal means» [13], an observance of rules and norms of politeness $[14,15]$.

The use of linguistic politeness notion in this study is closely related to the communicative goals of interlocutors in apology situation, and allows demonstrating its role in face-to-face interaction. In particular, politeness being a significant part of human communication is a social phenomenon, the essence of which is the regulation of interpersonal interaction balance. P. Brown and S. Levinson point out that the function of both ritual behavior and politeness in general is «the control of any social group over internal and external aggression» [16]. Linguistic politeness, in turn, creates a favorable atmosphere for communication, mitigates possible aggression and helps to achieve the goals. In other words, linguistic politeness promotes successful and conflict-free communication. However, «effective communication involves the processing of social as well as linguistic knowledge» [17]. Moreover, to maintain a communicative balance the interlocutors should be aware of each of their speech acts. The analysis of the empirical material showed that apology intention of the speaker can be expressed both with the help of etiquette fixed formulas, for example: - Oh, I'm so sorry, - he said, and stopped and stared. - It's quite all right, said Rosemary, smiling [18], and by using free statements acting as an apology in typical situations.
Such free statements as justifications, explanations, suggestions to repair damages, promises not to do it again, etc. can perform the function of apology themselves. For example: - I know somebody just like that, - she exclaimed. - A girl back home - Eula Becker, her name is. It never fails. Every single time we take her on a picnic. - Polly, - I said sharply, - It's a fallacy. Eula Becker doesn't cause the rain. She had no connection with the rain. You are guilty of Post Hoc if you blame Eula Becker. - I'll never do it again, - she promised contritely. Are you mad at me? I sighed. - No, Polly, I'm not mad [19].

However, the study revealed that the use of etiquette formulas together with free statements is more frequent than the use of etiquette formulas alone, since they increase the acting potential of apology formulas. For example: - Manfred, - Archer complained, - I'm still in bed. - Oh, I'm so sorry. A thousand apologies. I have been up since five-thirty and I... - That's all right, Manfred, Archer said crossly [20];

- You're a good girl, Jennie, - he said brokenly. You have been good to me. I've been hard and cross, but I'm an old man. You forgive me, don't you? - Oh, papa, please don't, - she pleaded, tears welling from her eyes. - You know I have nothing to forgive [21].

On the whole, the apology formulas are «corrective ritual idioms», the use of which does not depend on the nature of the committed offense [22]. The apology formulas are inherently manifestations of linguistic politeness, actualized in situations of interpersonal communication. The situation under consideration is characterized by the following components: 1) two, at least, communication participants: the speaker (the person who apologizes) and the addressee (the person to whom the apology is directed); 2) the damage (minor/serious); 3 ) the communication environment (place/time); 4) the verbal/nonverbal expression of the communicative intention [23].

It is to be emphasized that the damage (real or possible) is the cause of apology situation emergence. On the one hand, the damage degree influences the speaker, determining his choice of one or another way of expressing apology. On the other hand, the severity of the damage also affects the addressee, defining the nature of his reaction to the communicative actions of the speaker. For example: - Forgive me, papa, - she pleaded, - I'm so sorry. Oh, I'm so sorry. - I have prayed, - he said brokenly. - It is all right [21].

Based on the fact of the happened damage or the possibility of its occurrence, researchers distinguish between preventive (prospective) and misconduct (retrospective) apology [24]. In the communicative situation of prospective apology (getting attention, asking again, interrupting a conversation, ending a conversation, etc.), the speaker apologizes with the goal to mitigate the damage that he intends to inflict upon the addressee with his forthcoming verbal or nonverbal behavior. For example: - My dear, - I said favouring her with a smile, - we have now spent five evenings together. We have got along splendidly. It is clear that we are well matched. Hasty Generalization, - said Polly brightly. - I beg your pardon, - said I. - Hasty Generalization, - she repeated. 
How can you say that we are well matched on the basis of only five dates? [19].

The interlocutor's communicative competence allows the speaker to use prospective apology in an appropriate way, and the addressee to interpret it adequately and, thus, to maintain the interactional balance. For example: Oh, Edward, I'm sure the duchess would like to see your writing room. She has to go almost immediately. - I'm so sorry, but I must catch the three-eighteen from Tercanbury, - said the duchess. $<\ldots>-$ Would you like to see one of his manuscripts? - I'd love to, - said the duchess, - and then I simply must bolt [25].

In the communicative situation of retrospective apology, there is the existence of conflict relations between interlocutors at the moment of conversation, as the damage for the addressee is a fait accompli. For example: Lord St. Simon had by no means relaxed his rigid attitude, but had listened with a frowning brow and a compressed lip to this long narrative. - Excuse me, he said, - but it is not my custom to discuss my most intimate personal affairs in this public manner. - Then you won't forgive me? You won't shake hands before I go?

- Oh, certainly, if it would give you any pleasure. He put out his hand and coldly grasped that which she extended to him [26].

The speaker, apologizing, seeks to resolve the conflict and, thus, restore the previous harmonious relationships. «An honest and sincere apology has the potential to restore dignity and diminish fear of retaliation or even desire for vengeance on the receiving end» [27]. Using a verbal apology, the person tries to eliminate or mitigate the negative effect of the committed misconduct. That happens in this way: when making an apology, the speaker makes it clear that he admits the correctness of behavior norms, despite his negative action, which in fact «does not express his true position» and that his attitude towards the man, whose «territory» was violated, has not changed [22]. Apologies, which are the most effective «include a statement that the offence will not be repeated» [28]. Also «depending on how close the apologizer is to the offended person, he might choose to include humor to lighten the mood». Often this action helps to diffuse a tense atmosphere or to reduce the anger of the offended person [29].

Thereby, communicative behavior of a person in an apology situation reflects his psycho-emotional state, the level of his culture, life experience. It is an individual refraction of sociocultural and situational norms and rules in his communicative personality.

\section{Conflict communicative behavior}

As a rule, the question of politeness arises in potentially conflictual situations. The communicative behavior of the speaker is interpreted by the addressee as impolite if: 1) the person does not fulfill the expected norms/rules of politeness (does not say hello, does not apologize, does not thank, etc.); 2) the person chooses an inappropriate norms/rules of politeness, not acceptable in this situation, and in this status-role relationships of interlocutors; 3 ) the speaker negatively characterizes the addressee or the object of his personal sphere [30].

Communicative behavior of partners in daily social interaction may be directed not only to cooperation, but also may represent a removal from active participation in the situation or may be aimed at a conflict. Conflict is an integral part of human communication; it is involved in the development of interpersonal relationships [31]. Furthermore, the conflict can become a personality trait. In this case, it begins to manifest itself in all aspects of human communicative behavior [32].

In the current study, conflict is analyzed as a type of communication, which is based on contradictions in the views, attitudes, intentions and goals of interlocutors. One of the main causes of conflicts is the dissimilarity of people in terms of their life priorities, goals and values. The researchers note the difference between conflict and conflictual situation. Conflict is a process that has discrete characteristics, involves a beginning and an end. The moment when communicative actions reorganize and acquire a conflictual nature is considered to be the beginning of the conflict. Therefore, any situation that fixes a conflictual reality at any time interval from its beginning, is a specific conflictual situation [33].

So, conflict is a state of relations between communicants, which: 1) characterized by a clash of intentions, assessments, opinions, attitudes, etc.; 2) as a rule, accompanied by negative emotions; 3 ) has a formal structure: the beginning of conflict, the process of conflict and its end. Conflict is clearly manifested in an interpersonal communicative situation, which fixes it (the conflict between participants) at a specific time period, and is considered to be conflictual. Communicative behavior of interlocutors in a conflictual situation is characterized by confrontation between their opposing intentions, goals, assessments, views or attitudes. Situations potentially threatening the relationships of communicants: the manifestation of strong negative emotions in interpersonal relationships; the restoration of relations after conflict [34], in particular, the situation of apology and other.

The collected data of empirical material showed that the communicative behavior of partners in the apology situation is determined by two main trends - the desire for cooperation and the desire for conflict. The communicative behavior of the speaker is often cooperative, which, in our opinion, is related to the peculiarities of his communicative personality. For example: - I'm sorry, Connie. What I said was awful. That's all right, let's forget it. OK? [35].

The behavior of the addressee is characterized by the desire for conflict in those cases where the damage is great. As a result, he does not wish to forgive the guilty person (the speaker). In other words, in such situation, the intentions of the interlocutors collide (cooperative on the part of the speaker and conflictual on the part of the addressee).

To sum up, the communicative situation of apology can be both conflictual and potentially conflictual (that is, containing the prerequisites for a future conflict). Firstly, the real or possible damage affects the very fact of this situation occurrence. Damage is a conflictual 
phenomenon: in the situation of retrospective apology, the damage to the addressee has already been caused, so at the time of conversation, the interlocutors are in the state of conflict. Apology situation in this case is conflictual (at least at the initial stage of communication), because it fixes the conflict at this particular time interval. However, this fact does not exclude the possibility of its development into a cooperative one. For example: - Look, - Burke said, - I didn't come up here to talk about that. I forgot and I'm sorry and I apologize and I don't want you to hold it against me. - Forget it. $<\ldots>$ [20].

Secondly, in a situation where the addressee has suffered great moral or physical damage or, when relationships with the interlocutor do not have much value for the addressee, his verbal behavior may have «destructive content» [32] - he does not accept the apology. For example: - I acted mighty mean today, Becky, and I'm so sorry. I won't ever, ever do that way again, as long as ever I live - please make up, won't you? The girl stopped and looked him scornfully in the face. I'll thank you to keep yourself to yourself, Mr. Thomas Sawyer. I'll never speak to you again. - She tossed her head and passed on [36].

Such position inevitably leads to the aggravation of conflict and it often ends the relationship. In such a situation there is clearly the conflict of goals and interests of interlocutors - the speaker apologizes, and the addressee refuses to accept it. Therefore, this situation of communication is a conflict one.

Thirdly, in case of using apology as a means of addressing a stranger for the purpose of requesting information, etc. the situation is potentially conflictual, since the speaker takes up his (the addressee) time and makes him start a communicative process, intrudes on his/her privacy. The apology itself in this situation fulfills not only the function of appealing, but also helps to mitigate the possible negative effect of the speaker's forthcoming communicative behavior. For example: We were walking up the road from the hotel when a young man padded up behind us and greeted us in English. Hey man, - he said. - Excuse me for bothering you. - He had a thin face and pockmarked skin. His hair was plastered forward over his scalp to hide the fact that he was already balding. - I just wanted to offer you any help if I can. To find the way, or to give you any advices. Where are you from? - From England, - I said. We did not like the look of him and kept walking [37].

Fourthly, the situation of prospective apology may contain the prerequisites for a possible conflict, and also be a potentially conflictual communicative situation. For example: - I beg your pardon, sir, but there's no boat on the island [38].

This is explained by the fact, that the speaker does not always manage to achieve the goal to prevent the negative effect of his forthcoming words or actions with the help of apology, so the situation from the cooperative can turn into a conflictual one, since the addressee is often not satisfied with the apology (in case when the forthcoming damage is considerably large). Consequently, in real situations of communication, apologizing does not always help to achieve the success of interpersonal interaction. Quite often using prospective apology is not enough to prevent a possible conflict. Rude remarks of the addressee, obviously, represent the manifestation of conflictual communicative behavior, which often provokes the emergence of a conflict situation. For example: $-<\ldots>$ It's a wonder I wasn't bitten. - Never mind, dear, It's really my fault. I told him to put them there, - Mother apologized and then added, feeling that the guests needed some explanations, - they were suffering sunstroke, poor things. - Really, Mother! exclaimed Larry, - I think that's carrying things too far. - Oh, shut up, - said Leslie. - What I want to know is, when's he going to remove the bloody things? [39].

\section{Conclusion}

In general, human interaction in apology situation is the reflection of interlocutors' psycho-emotional states, level of culture, their relationships. Besides, it bears the imprint of the communication partners personalities, their life priorities, goals and values. Cooperative communicative behavior in the situation of apology is associated with the use of certain formulas and expressions that promote effective communication. The appropriate use of these language tools by participants of the interaction indicates the having of so-called communicative competence, which is one of the ways of regulating the relationship of communicants. «To manage conflict effectively you must be a skilled communicator» [40].

The results of the study confirm that both partners should contribute to an interactive process, coordinate their actions with the actions of the interlocutor, and also observe social and ethical norms and rules of communication: friendliness, mutual respect, the desire to smooth out potential aggression and not to encroach on the «territory» of the interlocutor. It may be achieved through the use of apologies. The etiquette formulas convey the meaning of apology in any situation, that is, they are always polite. They fulfill the etiquette function and do not introduce new logical content. Their goal is the regulation of daily social interaction. However, the situation of apology does not always develop according to the scenario provided by etiquette, since the communicative behavior of interlocutors can have both a cooperative and a conflict orientation. Often the circumstances of communication develop in such a way that the addressee of an apology does not accept it. Thus, the use of politeness formulas, in particular apologies, is not an absolute guarantee of conflict-free and successful communicative interaction. Despite all the verbal and nonverbal efforts of the speaker (the person who brings an apology), the situation of communication becomes/remains conflict.

\section{References}

1. M. Adenzato, M. Bucciarelli, Journal of Pragmatics 40, 608 (2008)

2. J. Wu, E. Mattingly, P. Kraemer, Computers in Human Behavior 52, 59 (2015)

3. M. J. Marr, Behavioural Processes 113, 75 (2015) 
4. E. Halperin, M.R. Tagar, Current Opinion in Psychology 17, 94 (2017)

5. S. Nowicki, M.P. Duke, Journal of nonverbal behavior 18, 9 (1994)

6. J.A. Russell, J.A. Bachorowski, J.M. FernandezDols, Annual review of psychology 54, 329 (2003)

7. R.M. Krauss, Y.S. Chen, P. Chawla, Advances in experimental social psychology 28, 389 (1996)

8. E. Dresner, S.C. Herring, Communication theory 20, 249 (2010)

9. A.B. Hostetter, Psychological Bulletin 137, 297 (2011)

10. I.A. Sternin, Communicative behavior. Russian and Finnish communicative behavior 1, 4 (2000)

11. E. Goffman, Interaction rituals. About behavior in direct communication (Suhrkamp, Frankfurt a. M.,1971)

12. T.S. Ryzhkova, Friendliness as the semantic constant of inner man's world. The inner world of man: emotions, cognition, communication, (FGBOU VO «HGU», Abakan, 2017)

13. T.S. Ryzhkova, Sociocultural aspect of friendliness, Social competence 1, 29 (2017)

14. F.H. Felemban, Social and Behavioral Sciences 46, $70(2012)$

15. W. Reich, Journal of Pragmatics 43, 1349 (2011)

16. P. Brown, S. Levinson, Politeness: Some Universals in Language Usage (CUP, Cambridge,1994)

17. E. Olshtain, A. Cohen, Sociolinguistics and language acquisition, 18-35, (1983)

18. K. Mansfield, In a German Pension: The Swing of the Pendulum, CD-ROM (Direct Media Publishing, Moscow, 2006)

19. M. Shulman, Love Is a Fallacy (Penguin, New York, 1974)

20. I. Shaw, The Troubled Air (Dell Book, New York, 1987)

21. T. Driser, Jennie Gerhardt (Progress Publishers, Moscow, 1972)

22. E. Goffman, The individual in public exchange (Suhrkamp, Frankfurt a. M.,1974)

23. Y.V. Tufanova, Bulletin of ISTU 2, 316 (2014)

24. R. Rathmayr, Pragmatics of apologies (Bonlau Verlag, Koln, Weimar, Wien, 1996)

25. W. S. Maugham, Cakes and Ale: The Skeleton in the Cupboard (Progress Publishers, Moscow, 1980)

26. A. Doyle, The Adventures of Sherlock Holmes, CDROM (Direct Media Publishing, Moscow, 2006)

27. J. Barkat, United Nations ombudsman \& Mediation services (2018), URL: http://www.un.org/en/ombudsman/apologies.shtml

28. J. Kador, Effective apology: mending fences, building bridges, and restoring trust (Berrett-Koehler Publishers, San Francisco, 2009)

29. S. Verner, Teaching Apologies (2018), URL: https://busyteacher.org/14345-how-to-teachapologies-esl-activities.html

30. N.I. Formanovskaya, Speech communication: communicative and pragmatic approach ( Russian language, Moscow, 2002)

31. L. Comparini, Journal of Pragmatics 57, 57 (2013)
32. M.A. Goncharov, Basic strategies of behavior in conflict. Self-promotion, interpersonal communication, leadership (REA named after G.V. Plekhanov, St. Petersburg, 2006)

33. B.I. Hasan, A. Sergomanov, The psychology of conflict and negotiations (Publishing Center «Academy», Moscow, 2007)

34. O.S. Issers, Communicative strategies and tactics of Russian speech (URSS, Moscow, 2003)

35. M. Lerner, The Doubts of His Heart (Clouder, Liverpool, 1995)

36. M. Twain, The adventures of Tom Sawyer, CD-ROM (Direct Media publishing, Moscow, 2006)

37. S. Stewart, Old serpent Nile. A journey to the source (John Murray (Pubs) Ltd, London, 1991)

38. A. Christie, Ten Little Niggers (Collins Crime Club, Lincolnshire, 1939)

39. G. Durrell, The Party, British National Corpus (An On-line Sample Version) URL:http://www.natcorp.ox.ac.uk

40. A. Layton, Resolving Conflict Situations (University of California, Berkeley, 2018) 